\title{
Kinetics of catalytic biomass pyrolysis using Ni-based functional materials
}

\author{
Hang Yang ${ }^{\mathrm{a}}$, Guozhao Ji ${ }^{\mathrm{b}, \mathrm{c} *}$, Peter T. Clough ${ }^{\mathrm{d}}$, Xiaoyin $\mathrm{Xu}^{\mathrm{e}}$, Ming Zhao ${ }^{\mathrm{a} *}$ \\ ${ }^{\text {a }}$ School of Environment, Tsinghua University, Beijing 100084, China \\ ${ }^{\mathrm{b}}$ School of Environmental Science \& Technology, Dalian University of Technology, \\ Dalian 116024, China \\ ${ }^{\mathrm{c}}$ Key Laboratory of Industrial Ecology and Environmental Engineering, Ministry of \\ Education, Dalian 116024, China \\ ${ }^{\mathrm{d}}$ Energy and Power Theme, Cranfield University, Cranfield, Bedfordshire, MK43 \\ 0AL, UK \\ ${ }^{\mathrm{e}}$ Department of Chemical Engineering, The University of Melbourne, Parkville,
} Victoria 3010, Australia.

Correspondence concerning this article should be addressed to Ming Zhao at ming.zhao@tsinghua.edu.cn; Tel: $\quad+86 \quad 10 \quad 62784701$ and Guozhao Ji at guozhao.ji@uqconnect.edu.au; Tel: +8641184706206 


\section{Abstract:}

The pyrolysis behaviors of three types of biomass (cellulose, sawdust and straw) in three cases (no catalyst, $\mathrm{Ni}-\mathrm{CaO}-\mathrm{Ca}_{2} \mathrm{SiO}_{4}$ and $\mathrm{Ni}-\mathrm{Ca}_{2} \mathrm{SiO}_{4}$ ) were investigated by non-isothermal thermogravimetric analysis. The non-isothermal pyrolysis was implemented with four different heating rates: 20,30, 40 and $50 \square / \mathrm{min}$ and the yield rates of the produced gases were measured by TG-MS. For kinetic analysis, the activation energy was obtained using four isoconversional analysis methods (Flynn-Wall-Ozawa (FWO) method, Kissinger-Akahira-Sunose (KAS) method, Starink method, and the Miura distributed activation energy model (DAEM)). Ni-CaO-Ca $-\mathrm{SiO}_{4}$ and $\mathrm{Ni}-\mathrm{Ca}_{2} \mathrm{SiO}_{4}$ was found to intensify the decomposition of biomass to produce more $\mathrm{H}_{2}$ and $\mathrm{CO}$. The correlation $\mathrm{R}^{2}$, of all fitting lines in all cases, was above 0.9 which demonstrated that FWO, KAS, Starink methods and DAEM were suitable for calculating the activation energy of the biomass catalytic pyrolysis. $\mathrm{Ni}-\mathrm{CaO}-\mathrm{Ca}_{2} \mathrm{SiO}_{4}$ showed the obvious catalytic effects in the decrease of activation energy of biomass pyrolysis to produce additional $\mathrm{H}_{2}$ and $\mathrm{CO}$ from the breakage of light organic molecules.

Keywords: Biomass, Pyrolysis, Catalytic, Kinetic analysis, Functional materials.

\section{Introduction}

With the advancement of global warming and depletion of readily accessible fossil fuel resources, renewable energy has attracted more and more attention in industry and within the scientific community. In replacement of fossil fuels, biomass energy has been suggested as a sustainable alternative, whereby its utilization is a carbon-neutral process, as any $\mathrm{CO}_{2}$ released in its conversion to energy was sourced from atmospheric $\mathrm{CO}_{2}$ [1]. Biomass energy currently accounts for about $10 \%$ of world's energy and has already provided roughly $35 \%$ of the energy demand in developing countries $[2,3]$. Biomass resources can include agricultural crop residues, forestry residues, animal manure, energy crops, and municipal solid waste [3-7]. In 
China, it is estimated that each year there are potentially $\sim 10,818 \mathrm{PJ}$ of crop residues and $\sim 4,701$ PJ of forestry residues [8]. The conversion of biomass to energy is undertaken via two pathways: thermochemical and biological methods [9]. Pyrolysis is not only an efficient thermochemical conversion technology but also the first preceding process of other thermochemical conversions such as gasification, liquefaction, carbonization and combustion [10]. Therefore, a comprehensive understanding of the products yields and mass loss during biomass pyrolysis can promote the development of industrial biomass utilization.

Non-isothermal analysis is a dynamic method, widely used in analysis of biomass pyrolysis. Thermogravimetric analysis (TGA) is the typical method of conducting non-isothermal analysis and by analyzing thermogravimetric data collected at different heating rates with a model-fitting method one can estimate the kinetic triplets including activation energy, frequency factor and reaction mechanism $[11,12]$. Understanding the kinetics is a key step for the development of pyrolysis technology. Pyrolysis can be performed in reactors of multiple size ranges, but the performance of the pyrolysis process within these reactors will all be affected by the kinetics or mass and heat transfer. To predict and assess the performance of a reactor, kinetic data must be coupled to the heat and mass transfer models [13]. Without a full and deep understanding of kinetics, it is impossible to build a reactor model. The kinetic models of biomass pyrolysis reactions have been developed in recent research, which are classified into five models: 1) one-step global model based on model-fitting method, 2) global model based on model-free method, 3) multi-step successive model, 4) semi-global model, and 5) distributed activation energy model [14].

The one-step global model often describes the pyrolysis of cellulose through a first-order irreversible rate reaction, from which the apparent activation energy of an equivalent global reaction can be obtained. The application of kinetic studies on cellulose present good performance by one-step global model-fitting method. However, due to complex composition of biomass, it cannot be simply used as a 
global reaction model to represent real biomass pyrolysis. The global model based on the model-free method (isoconversional method) does not need any prior assumption of the reaction model and obtains accurate kinetic parameters based on a series of thermogravimetric (TG) data under different heating rates [15-17]. The multi-step successive model analyzes the kinetics of the biomass pyrolysis based on the one-step global model. This model always divides the pyrolysis into a series of stages according to the temperature and mass loss, and obtains the kinetic parameters of these stages. The semi-global model is more complicated than the multi-step successive model since it involves several reactions including the solid phase reactions and subsequent reactions of tar and gases. The analysis of kinetic reaction by the semi-global model appears more detailed as it can also consider the reaction mechanisms. The distributed activation energy model (DAEM), based on the semi-global model, assumes that infinite, independent, parallel reactions compose the pyrolysis process and their activation energies can be described by a continuous probability function $f(E)[14,18,19]$. The DAEM has recently been employed to analyze the pyrolysis kinetics of coal and complex biomass [10, 13, 19-23].

Most studies focus on the kinetics of biomass pyrolysis [24], but less research has paid attention to the kinetics of catalytic pyrolysis of biomass. Many researchers have studied the influence of the catalyst on yields of gaseous products [25-27] and bio-oil [28-31] from biomass pyrolysis. Recent studies have found that the multi-functional material Ni-CaO-Ca $\mathrm{SiO}_{4}$ significantly promoted the gasification performance of biomass [25]. This type of material could increase the kinetics by catalysis, shift the thermodynamics by in-situ $\mathrm{CO}_{2}$ capture, and stabilize its own structure by its polymorphic spacer. However, with this material the kinetic performance of biomass pyrolysis has not been systematically investigated. In order to understand the progress of biomass catalyst pyrolysis, this study aims to employ DAEM to analyze the kinetics of biomass and obtain the kinetic parameters. Combining the evolution of gaseous products, by TG-MS analysis, the effects of the functional material on the 
products and kinetics of catalytic biomass pyrolysis have been further investigated.

\section{Experimental}

\subsection{Materials}

\subsubsection{Biomass feedstock}

Straw, sawdust and cellulose were selected as biomass feedstocks in this study. The straw used was from Suqian in Jiangsu Province, China. The sawdust used was pine wood from Bingzhou in Sandong Province, China. Cellulose was sourced as methylcellulose, which was purchased from SIGMA-ALDRICH. Before carrying out the pyrolysis experiments, these samples were milled and sieved into powders with particle diameters less than $180 \mu \mathrm{m}$. The sieved samples were dried at $105^{\circ} \mathrm{C}$ for $12 \mathrm{~h}$. After drying, the carbon, hydrogen, oxygen, nitrogen, and sulfur contents were measured using an EA3000 Elemental Analyzer (CHN/O) (Eurovector, Italy) and a 5E-AS3200B Sulfur Analyzer (S) (Changsha Kaiyuan Instrument Co., Ltd.). The proximate analysis results, including volatiles matter, fixed carbon and ash content, were obtained from an ELTRA industrial analyzer (Germany). The biomass's ultimate and proximate analyses are shown in Table 1.

Table 1. Biomass elemental analysis and proximate analysis

\begin{tabular}{|c|c|c|c|c|c|c|c|c|c|}
\hline Biomass & C $(\%)$ & H (\%) & $\mathrm{O}(\%)$ & N (\%) & S (\%) & $\begin{array}{c}\text { Volatiles } \\
\text { (\%) }\end{array}$ & $\begin{array}{l}\text { Ash } \\
(\%)\end{array}$ & $\begin{array}{c}\text { Fixed carbon } \\
(\%)\end{array}$ & $\begin{array}{c}\text { Combustible } \\
\text { (\%) }\end{array}$ \\
\hline Straw & 41.85 & 5.56 & 39.40 & 1.40 & 0.16 & 71.61 & 11.63 & 16.76 & 88.37 \\
\hline Sawdust & 48.22 & 6.22 & 44.70 & 0.49 & 0.05 & 81.26 & 0.31 & 18.43 & 99.69 \\
\hline Cellulose & 44.44 & 6.17 & 49.39 & 0 & 0 & 94.30 & 0 & 5.70 & 100.00 \\
\hline
\end{tabular}

\subsubsection{Functional materials}

This study chose $\mathrm{Ni}-\mathrm{CaO}-\mathrm{Ca}_{2} \mathrm{SiO}_{4}$ and $\mathrm{Ni}-\mathrm{Ca}_{2} \mathrm{SiO}_{4}$ as pyrolysis functional materials. In the functional material, $\mathrm{Ni}$ acts as catalyst in cracking $\mathrm{C}-\mathrm{C}, \mathrm{C}-\mathrm{H}$ and $\mathrm{O}-\mathrm{H}$ bonds [25]. $\mathrm{CaO}$ is the $\mathrm{CO}_{2}$ sorbent to shift the reforming reactions towards $\mathrm{H}_{2}$ direction $[32,33] . \mathrm{Ca}_{2} \mathrm{SiO}_{4}$ works as stabilizer to combat material sintering, and it 
does not absorb $\mathrm{CO}_{2}$. The synthesis procedures of the two functional materials were similar, both underwent freeze-drying, calcination, and reduction synthesis. The $\mathrm{Ni}-\mathrm{CaO}-\mathrm{Ca}_{2} \mathrm{SiO}_{4}$ and $\mathrm{Ni}-\mathrm{Ca}_{2} \mathrm{SiO}_{4}$ were prepared by adding calcium acetate $\left(\mathrm{Ca}\left(\mathrm{C}_{2} \mathrm{H}_{3} \mathrm{O}_{2}\right)_{2}\right)$, tetraethyl orthosilicate (TEOS, $\left.\mathrm{Si}\left(\mathrm{OC}_{2} \mathrm{H}_{5}\right)_{4}\right)$ and nickel (II) nitrate hexahydrate $\left(\mathrm{Ni}\left(\mathrm{NO}_{3}\right)_{2} \cdot 6 \mathrm{H}_{2} \mathrm{O}\right)$ into dilute nitric acid $\left(\mathrm{HNO}_{3}\right)$. The homogenous precursors were frozen at $-80^{\circ} \mathrm{C}$ and then freeze-dried under vacuum for 24 hours. Precursors were calcined at $850{ }^{\circ} \mathrm{C}$ in air for $1 \mathrm{~h}$. Before the pyrolysis test, 1-h reduction for the catalyst was executed under 5 vol. $\% \mathrm{H}_{2}$ in $\mathrm{N}_{2}$ hour at $750{ }^{\circ} \mathrm{C}$. The detailed synthesis procedure was reported in Ji. et al. [25]. The Ni contents of Ni-CaO-Ca $\mathrm{SiO}_{4}$ and $\mathrm{Ni}-\mathrm{Ca}_{2} \mathrm{SiO}_{4}$ both were 20 wt.\%.

\subsection{TG-MS experiment}

The pyrolysis experiments of this study were conducted using thermogravimetric mass spectrometry (TG-MS). For thermogravimetric analysis, the thermogravimetric analyzer SDT Q600 (TA) was used. The pyrolytic gas analysis, also called evolved gas analysis, was performed using the British Hiden's HPR20 mass spectrometer (MS). The MS was connected to the TGA outlet with a heated connection $\left(200{ }^{\circ} \mathrm{C}\right)$ to avoid the condensation of products. For a comparison purpose, biomass pyrolysis without any catalyst present was also carried out, using around 4-5 mg. For biomass pyrolysis conducted in the presence of the functional materials, the functional materials and biomass were mixed with 1:1 mass ratio and around 6-7 mg mixture sample were used. Before the pyrolysis experiments, an argon flow of $500 \mathrm{ml} / \mathrm{min}$ was used to clean the furnace of the TGA to eliminate any air interference. Then the furnace was heated from room temperature up to $100{ }^{\circ} \mathrm{C}$ at a heating rate of $10{ }^{\circ} \mathrm{C} / \mathrm{min}$ and kept at this temperature for 10 minutes to drive off any moisture from the biomass. For the kinetic analysis, the mass loss of pyrolysis was measured under different heating rates of $20,30,40$, and $50{ }^{\circ} \mathrm{C} / \mathrm{min}$ from $100{ }^{\circ} \mathrm{C}$ to $800{ }^{\circ} \mathrm{C}$ in an argon flow of $500 \mathrm{ml} / \mathrm{min}$. The mass/charge, $\mathrm{m} / \mathrm{z}$, signals at $2,15,18,28,40$, and 44 were recorded continuously by the MS and represented the corresponding gases: $\mathrm{H}_{2}, \mathrm{CH}_{4}$, 
$\mathrm{H}_{2} \mathrm{O}, \mathrm{CO}, \mathrm{Ar}$, and $\mathrm{CO}_{2}$. The gas products were determined through a semi-quantitative method based on the signals of Ar and Ar flow (Details and limitation discussion can be referred to from our previous published works [26, 34-37]).

\subsection{Kinetic analysis}

During the pyrolysis process, the reaction rate can be expressed as,

$$
\frac{\mathrm{d} \alpha}{\mathrm{d} t}=k(T) f(\alpha)
$$

where $k(T)$ is reaction rate constant, which is not really a constant just a function depending on the temperature, and $\alpha$ is the conversion rate of reactant. $f(\alpha)$ is the reaction model which depends on the reaction mechanism. The reaction rate constant is described by Arrhenius equation as follows,

$$
k(T)=k_{0} \exp \left(-\frac{E}{R T}\right)
$$

where $k_{0}, E, R$ and $T$ are frequency factors (pre-exponential factor, $\min ^{-1}$ ), the activation energy $(\mathrm{kJ} / \mathrm{mol})$, the universal gas constant $\left(8.314 \times 10^{3} \mathrm{~kJ} / \mathrm{mol}\right)$, and temperature $(\mathrm{K})$, respectively. During a non-isothermal TGA process, the heating rate is,

$$
\beta=\frac{\mathrm{d} T}{\mathrm{~d} t}
$$

Using Eq. (1), Eq. (2) and Eq. (3), we can obtain Eq. (4),

$$
\frac{\mathrm{d} \alpha}{\mathrm{d} T}=\frac{k_{0}}{\beta} \exp \left(-\frac{E}{R T}\right) f(\alpha)
$$

upon integration of Eq. (4), Eq. (5) is obtained as,

$$
G(\alpha)=\int_{0}^{T} \frac{k_{0}}{\beta} \exp \left(-\frac{E}{R T}\right) \mathrm{d} T
$$

Most kinetic analysis methods are differential methods based on Eq. (4), and Eq. 
(5) represents integral methods [38-41].

In this study, the apparent activation energy, $E$, was compared with four methods: Flynn-Wall-Ozawa (FWO) method, Kissinger-Akahira-Sunose (KAS) method, Starink method, and the Miura distributed activation energy model.

\subsubsection{Flynn-Wall-Ozawa method}

Using Eq. (5) and the Doyle's approximation to the temperature integral, Eq. (6) is derived [42],

$$
\ln (\beta)=\ln \left[\frac{0.0048 * k_{0} E}{R G(\alpha)}\right]-1.052 \frac{E}{R T}
$$

The temperature, $T$, and conversion, $\alpha$, can be measured from TGA experiments. The Arrhenius plot can be obtained by plotting $\ln (\beta)$ vs $1 / T$ at the same conversion for different heating rates, $\beta . E$ is estimated by the slope of the linear-fitting.

\subsubsection{Kissinger-Akahira-Sunose method}

The KAS method can be described as follows [43],

$$
\ln \left(\frac{\beta}{T^{2}}\right)=\ln \left[\frac{k_{0} R}{E G(\alpha)}\right]-\frac{E}{R T}
$$

At each degree of conversion, the four pairs of $\ln \left(\beta / T^{2}\right)$ and $1 / T$ data points from different heating rates were plotted and fitted to line while $E$ is estimated by the slope.

\subsubsection{Starink method}

Through analyzing Eq. (6) and Eq. (7) and using approximations of the temperature integral, Starink got the following expression [44],

$$
\ln \left(\frac{\beta}{T^{1.92}}\right)=C_{S}-1.0008 \frac{E}{R T}
$$

Arrhenius graph is obtained by plotting $\ln \left(\beta / T^{1.92}\right)$ vs $1 / T$ at the same conversion for different heating rates. $E$ can be estimated from the slope of a 
linear-fitting curve.

\subsubsection{Distributed activation energy model}

The distributed activation energy model was proposed originally by Vand [45], which had been employed to analyze the conventional fossil fuel pyrolysis kinetics $[20,21,46]$. For the biomass pyrolysis experiments, the DAEM model was used as it can account for the kinetics of complex reactions, it assumes that the pyrolysis of biomass is composed of a large number of independent parallel first-order reactions with different activation energies and frequency factors. The difference in activation energies of these reactions is represented by the activation energy distribution function $f(E)$. In this study, an integral method, which was proposed by Miura [40], was employed to analyze kinetics and obtained kinetic parameters $E$ and $k_{0}$. In the model the correlation between volatiles and time can be expressed as,

$$
1-\frac{V}{V^{*}}=\int_{0}^{\infty} \exp \left(k_{0} \int_{0}^{t} e^{-\frac{E}{R T}} \mathrm{~d} t\right) f(E) \mathrm{d} E
$$

where $V$ is the amount of mass loss, $V^{*}$ is the total mass loss in experiment $(\alpha=$ $\left.V / V^{*}\right)$, and $k_{0}$ is the frequency factor corresponding to the $E$, and $f(E)$ is distribution of activation energies. The variables inside the integral of Eq. (9) can be evaluated as,

$$
\Phi(E, T)=\exp \left(k_{0} \int_{0}^{t} e^{-\frac{E}{R T}} \mathrm{~d} t\right) \cong \exp \left(-\frac{k_{0}}{\beta} \int_{T_{0}}^{T} e^{-\frac{E}{R T}} \mathrm{~d} T\right)
$$

where $\beta$ is the heating rate, and $\Phi(E, T)$ is the function that changes steeply with $E$ at a given temperature. $\Phi(E, T)$ was approximated by a step function $U$ at an activation energy $E=E_{S}$ for a selected temperature $T$. Then Eq. (9) can be simplified as:

$$
\frac{V}{V^{*}} \cong 1-\int_{E_{S}}^{\infty} f(E) \mathrm{d} E=\int_{0}^{E_{S}} f(E) \mathrm{d} E
$$

The DAEM activation energies, $E_{s}$, were chosen to satisfy $\Phi\left(E_{s}, T\right) \cong 0.58$, 
with the approximate equation for $\Phi(E, T)$ :

$$
\Phi(E, T)=\exp \left(-\frac{k_{0} R T^{2}}{\beta E} e^{-\frac{E}{R T}}\right)
$$

The relationship between $E_{s}, k_{0}$, and $T$ is as follows:

$$
\frac{0.545 \beta E_{S}}{k_{0} R T^{2}}=e^{-\frac{E_{S}}{R T}}
$$

This approximation is that only a reaction having $E_{S}$ occurs at the specified $T$ and $\beta$. This approximation is given mathematically by,

$$
\frac{\mathrm{d} V}{\mathrm{~d} t} \cong \frac{\mathrm{d}(\Delta V)}{\mathrm{d} t}=k_{0} e^{-\frac{E}{R T}}\left(\Delta V^{*}-\Delta V\right)
$$

An actual reaction was approximated by a set of reactions. Eq. (14) shows that the overall rate can be approximated by the rate of the $n$-th reaction at the temperature, $T$, while only the $n$-th reaction is occurring. In Eq. (14), $V$ is the amount of mass loss and $V^{*}$ is the total mass loss for the $n$-th reaction. The $E$ and $k_{0}$ of the $n$-th reaction are both constants and Eq. (14) can be integrated to form the following,

$$
1-\frac{\Delta V}{\Delta V^{*}}=\Phi(E, T) \cong \exp \left(-\frac{k_{0} R T^{2}}{\beta E} e^{-\frac{E}{R T}}\right)
$$

Then the natural logarithm of Eq. (15) is obtained as follows:

$$
\ln \left(\frac{\beta}{T^{2}}\right)=\ln \left(\frac{k_{0} R}{E}\right)+=\ln \left[-\ln \left[\left(1-\frac{\Delta V}{\Delta V^{*}}\right)\right]\right]-\frac{E}{R} \frac{1}{T}
$$

Combining with $1-\frac{\Delta V}{\Delta V^{*}}=\Phi\left(E_{S}, T\right) \cong 0.58$, Eq. (16) can be rewritten as follows:

$$
\ln \left(\frac{\beta}{T^{2}}\right)=\ln \left(\frac{k_{0} R}{E}\right)+0.6075-\frac{E}{R} \frac{1}{T}
$$

The Arrhenius plot is obtained by plotting $\ln \left(\beta / T^{2}\right)$ vs $1 / T$ at the selected $\alpha$ values for different heating rates. $E$ and $k_{0}$ are estimated by the slope and intercept 
of the linear-fitting curve, respectively. The $T$ and $\alpha$ data can be obtained from TGA experiments.

\section{Results and discussion}

3.1. Thermal analysis
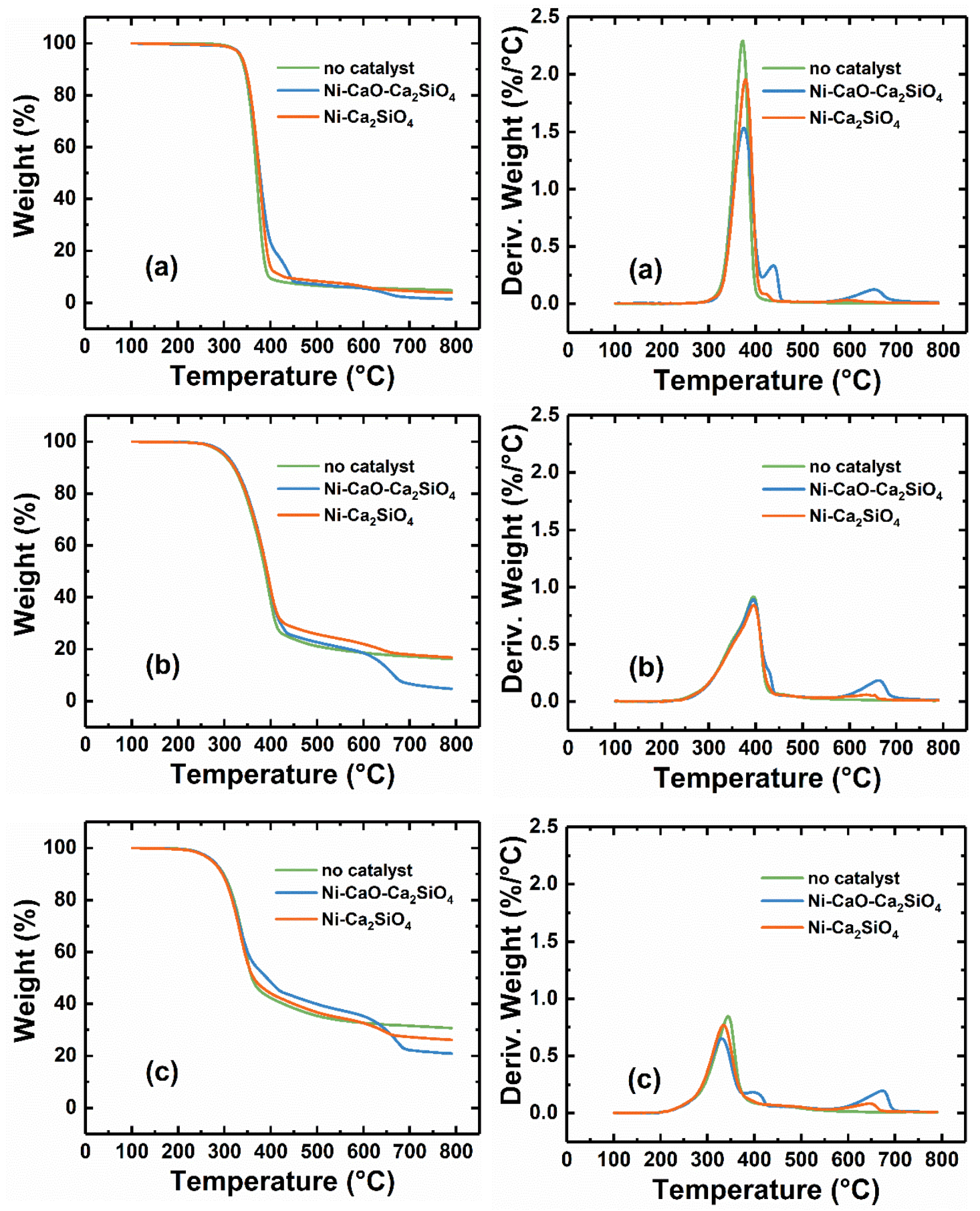

Fig. 1. TG and DTG curves of (a) cellulose, (b) straw, and (c) sawdust under heating rate of $50{ }^{\circ} \mathrm{C} / \mathrm{min}$.

The thermogravimetric analysis from the pyrolysis of different biomasses (cellulose, straw and sawdust) with different cases, no catalyst, $\mathrm{Ni}-\mathrm{Ca}_{2} \mathrm{SiO}_{4}$ and 
Ni-CaO-Ca $\mathrm{SiO}_{4}$, are shown in Fig. 1. (For a comparison purpose, overall weight did not contain the weight of functional materials.) All of samples were dried and ensured a stable mass reading at $100{ }^{\circ} \mathrm{C}$ for $10 \mathrm{~min}$ before pyrolysis began. The main mass loss of each biomass sample started from $200{ }^{\circ} \mathrm{C}$ and for the biomass samples with no functional material present the main devolatilization was completed at $600{ }^{\circ} \mathrm{C}$. The residual mass fraction of cellulose, sawdust and straw was $4.9 \%, 16.3 \%$, and $30.8 \%$, respectively, which indicates that the pyrolysis of straw without any catalyst produces more pyrolysis residues, likely because the straw has a higher inorganic constituent make up. Comparing the addition of $\mathrm{Ni}-\mathrm{Ca}_{2} \mathrm{SiO}_{4}$ and $\mathrm{Ni}-\mathrm{CaO}-\mathrm{Ca}_{2} \mathrm{SiO}_{4}$, the latter led to an additional mass loss between $600^{\circ} \mathrm{C}$ and $700^{\circ} \mathrm{C}$, this was because the $\mathrm{CaO}$ absorbed $\mathrm{CO}_{2}$ which had been produced at lower temperature to form $\mathrm{CaCO}_{3}$, and then as the temperature rose beyond the equilibrium position the $\mathrm{CaCO}_{3}$ decomposed to release the $\mathrm{CO}_{2}$. Furthermore, it can be noted that the $\mathrm{CaO}$ addition led to a lower residual mass at the end of the pyrolysis, hinting at its ability to catalytically shift the pyrolysis. As shown in the Fig. 1(a), the pyrolysis process of cellulose without catalyst was sharp and simple, since the DTG curve showed only one peak at $375^{\circ} \mathrm{C}$. Comparing the DTG curves of the cellulose with $\mathrm{Ni}_{-} \mathrm{Ca}_{2} \mathrm{SiO}_{4}$, and cellulose with $\mathrm{Ni}-\mathrm{CaO}-\mathrm{Ca}_{2} \mathrm{SiO}_{4}$, it showed two new two peaks at $438{ }^{\circ} \mathrm{C}$ and $653{ }^{\circ} \mathrm{C}$, respectively, which was attributed to the effect of $\mathrm{CaO}$. As shown in Fig. 1(b) and (c), the peaks of DTG curves of straw and sawdust without catalyst appeared to be wider and more complex, which resulted from the decomposition of hemicelluloses and lignin, which were not present in the comparison DTG peaks of cellulose observable in Fig. 1(a). After adding functional materials, the height of DTG curves decreased in a similar manner. For sawdust with Ni-CaO-Ca $\mathrm{SiO}_{4}$, the two additional new peaks, resulted from catalytic effects, occur at the $430{ }^{\circ} \mathrm{C}$ and $662{ }^{\circ} \mathrm{C}$, while for straw, new peaks occurred at $397^{\circ} \mathrm{C}$ and $673{ }^{\circ} \mathrm{C}$. All peaks around $650-673{ }^{\circ} \mathrm{C}$ is mainly due to the $\mathrm{CaCO}_{3}$ calcination reaction. This result indicated that the catalytic effect of $\mathrm{Ni}-\mathrm{CaO}-\mathrm{Ca}_{2} \mathrm{SiO}_{4}$ in the devolatilization process occurred over temperature range 
$390-440{ }^{\circ} \mathrm{C}$.

3.2. Gas product analysis
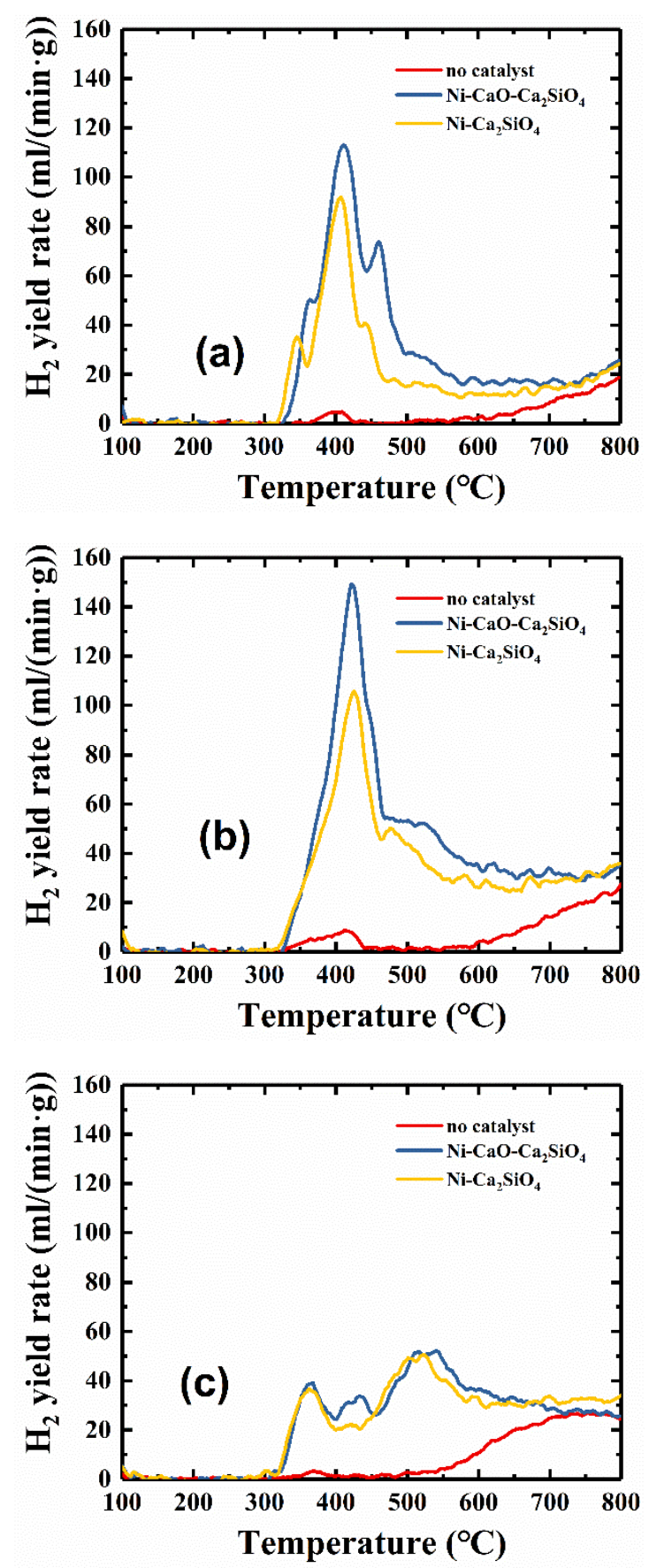

Fig. 2. $\mathrm{H}_{2}$ yield rate of (a) cellulose, (b) sawdust, (c) straw under different catalyst conditions.

During the pyrolysis of biomass, $\mathrm{H}_{2}, \mathrm{CO}$ and $\mathrm{CO}_{2}$ were main gas products measured, $\mathrm{CH}_{4}$ was also measured but was present in too low yields to make any meaning discussion in this paper. Fig. 2 shows the $\mathrm{H}_{2}$ yield rate of (a) cellulose, (b) sawdust, (c) straw without any catalyst and with $\mathrm{Ni}-\mathrm{CaO}-\mathrm{Ca}_{2} \mathrm{SiO}_{4}$ and $\mathrm{Ni}-\mathrm{Ca}_{2} \mathrm{SiO}_{4}$ 
present. Without any catalyst, the $\mathrm{H}_{2}$ yield rate of all biomass had a little peak between $310{ }^{\circ} \mathrm{C}$ and $450{ }^{\circ} \mathrm{C}$, and after $550{ }^{\circ} \mathrm{C}$ the yield rate began to increase, significantly higher than previous peaks, which was due to the multiply action that fixed carbon and vapor produced in previous pyrolysis undergoing the water-gas reaction (Eq. 18) to produce $\mathrm{H}_{2}$ and $\mathrm{C}-\mathrm{H}$ bonds breaking at the higher temperatures.

$$
\mathrm{H}_{2} \mathrm{O}+\mathrm{C} \rightarrow \mathrm{H}_{2}+\mathrm{CO} \#(18)
$$

There was a common feature to all samples under three conditions that $\mathrm{H}_{2}$ began to appear around $310{ }^{\circ} \mathrm{C}$. Cellulose and straw with functional materials present displayed a similar feature that at around $400{ }^{\circ} \mathrm{C}$ the max yield rate of $\mathrm{H}_{2}$ corresponded to the sharp decomposition in the DTG curves (Fig. 1). But sawdust with two functional materials had two peaks of $\mathrm{H}_{2}$ yield rate, between $360-370{ }^{\circ} \mathrm{C}$ and between $500-550^{\circ} \mathrm{C}$. Furthermore, sawdust with $\mathrm{Ni}-\mathrm{CaO}-\mathrm{Ca}_{2} \mathrm{SiO}_{4}$ had a third peak between $410-440{ }^{\circ} \mathrm{C}$. The $\mathrm{H}_{2}$ yield rate of cellulose and straw were more intense and concentrated than straw under catalytic conditions. As observed in Fig. 2, $\mathrm{Ni}-\mathrm{CaO}-\mathrm{Ca}_{2} \mathrm{SiO}_{4}$ can catalyze the pyrolysis of cellulose and sawdust to produce more $\mathrm{H}_{2}$ than $\mathrm{Ni}-\mathrm{Ca}_{2} \mathrm{SiO}_{4}$, but the impact of $\mathrm{CaO}$ to straw to produce $\mathrm{H}_{2}$ was insignificant which was due to the interaction between the $\mathrm{CaO}$ and inorganic substance of straw. 

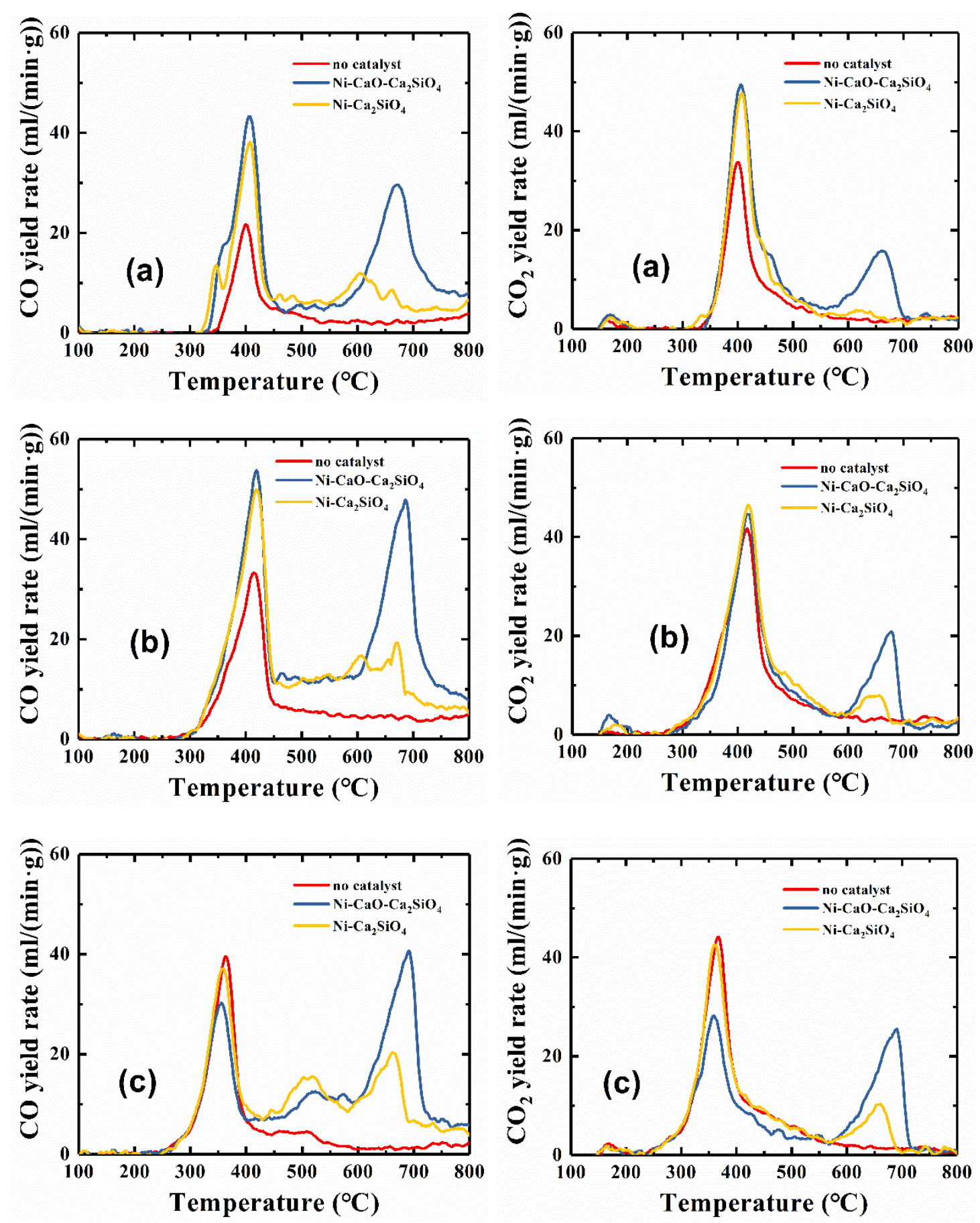

Fig. 3. $\mathrm{CO}$ and $\mathrm{CO}_{2}$ yield rate of (a) cellulose, (b) sawdust and (c) straw with different cases (no catalyst, $\mathrm{Ni}-\mathrm{CaO}-\mathrm{Ca}_{2} \mathrm{SiO}_{4}$ and $\mathrm{Ni}-\mathrm{Ca}_{2} \mathrm{SiO}_{4}$ ).

Fig. 3 shows the $\mathrm{CO}$ and $\mathrm{CO}_{2}$ yield rate of (a) cellulose, (b) sawdust and (c) straw with three cases (no catalyst, $\mathrm{Ni}-\mathrm{CaO}-\mathrm{Ca}_{2} \mathrm{SiO}_{4}$ and $\mathrm{Ni}-\mathrm{Ca}_{2} \mathrm{SiO}_{4}$ ). In the lower temperature range (below $600{ }^{\circ} \mathrm{C}$ ), the peaks of $\mathrm{CO}$ and $\mathrm{CO}_{2}$ yield rate curves of 
cellulose and straw without catalyst occurred around $400{ }^{\circ} \mathrm{C}$, but the peak for sawdust appeared at $\sim 365^{\circ} \mathrm{C}$. A common feature to all samples without catalyst was that the yield of $\mathrm{CO}$ and $\mathrm{CO}_{2}$ is concurrent. For cellulose and straw, the peak of biomass with $\mathrm{Ni}-\mathrm{CaO}-\mathrm{Ca}_{2} \mathrm{SiO}_{4}$ and $\mathrm{Ni}-\mathrm{Ca}_{2} \mathrm{SiO}_{4}$ happened to coincide between $300{ }^{\circ} \mathrm{C}$ and $450{ }^{\circ} \mathrm{C}$, which implied the catalysis of $\mathrm{CaO}$ to produce $\mathrm{CO}$ and $\mathrm{CO}_{2}$ is not obvious during this temperature range. For straw it showed a distinct difference for the formation rate of $\mathrm{CO}$ and $\mathrm{CO}_{2}$, however the addition of $\mathrm{Ni}-\mathrm{Ca}_{2} \mathrm{SiO}_{4}$ had no effect on the peak between 250-400 ${ }^{\circ} \mathrm{C}$. At higher temperatures, from $550-700{ }^{\circ} \mathrm{C}$, both sets of functional materials caused secondary peaks to appear for $\mathrm{CO}$ and $\mathrm{CO}_{2}$ to appear in all biomass samples, which could be due to the fact that the $\mathrm{Ni}$ and $\mathrm{CaO}$ facilitated the formation of $\mathrm{CO}$ and $\mathrm{CO}_{2}$ from tar cracking. In the cases with $\mathrm{Ni}-\mathrm{CaO}-\mathrm{Ca}_{2} \mathrm{SiO}_{4}, \mathrm{CO}$ and $\mathrm{CO}_{2}$ had high secondary peaks due to the $\mathrm{CaCO}_{3}$ calcination reaction (Eq. 19) and subsequent Boudouard reaction with the remaining char (Eq. 20).

$$
\mathrm{CaCO}_{3} \Leftrightarrow \mathrm{CaO}+\mathrm{CO}_{2} \#(19)
$$

$$
\mathrm{CO}_{2}+\mathrm{C} \Leftrightarrow 2 \mathrm{CO \#}(20)
$$

The evolution trends of $\mathrm{CO}_{2}$ in the cases with $\mathrm{Ni}-\mathrm{CaO}-\mathrm{Ca}_{2} \mathrm{SiO}_{4}$ and $\mathrm{Ni}-\mathrm{Ca}_{2} \mathrm{SiO}_{4}$ were very similar. The only difference was that the secondary peaks that occurred at high temperature range had different heights. This difference reflected the $\mathrm{CO}_{2}$ capture and release process due to the presence of $\mathrm{CaO}$. As is known, $\mathrm{CaO}$ has a small catalytic effect for biomass gasification, thus the case with $\mathrm{Ni}-\mathrm{CaO}-\mathrm{Ca}_{2} \mathrm{SiO}_{4}$ should have displayed more $\mathrm{CO}_{2}$. But at intermediate temperatures $\left(<550{ }^{\circ} \mathrm{C}\right)$, this expected phenomenon was not observed. On the contrary, we observed less $\mathrm{CO}_{2}$ than the case with Ni-Ca $\mathrm{SiO}_{4}$, because at such temperatures, $\mathrm{CO}_{2}$ was captured by the free $\mathrm{CaO}$. When the temperature was increased above $600{ }^{\circ} \mathrm{C}$, the $\mathrm{CO}_{2}$ rate of $\mathrm{Ni}-\mathrm{CaO}-\mathrm{Ca}_{2} \mathrm{SiO}_{4}$ evidently overtook that of $\mathrm{Ni}-\mathrm{Ca}_{2} \mathrm{SiO}_{4}$. This was caused by the $\mathrm{CO}_{2}$ release at such high temperatures, noted in Eq. (19), hence causing a much higher $\mathrm{CO}_{2}$ peak for 
$\mathrm{Ni}-\mathrm{CaO}-\mathrm{Ca}_{2} \mathrm{SiO}_{4}$.

The functional materials showed a similar influence on gas yield rates from cellulose and straw, but was different for sawdust. As demonstrated in Fig. 4, the common influence of functional material to all samples was that $\mathrm{Ni}-\mathrm{CaO}-\mathrm{Ca}_{2} \mathrm{SiO}_{4}$ and $\mathrm{Ni}-\mathrm{Ca}_{2} \mathrm{SiO}_{4}$ enhanced the yield of $\mathrm{H}_{2}$ and $\mathrm{CO}$. Sawdust had better hydrogen production potential from pyrolysis than cellulose or straw. The addition of $\mathrm{CaO}$ showed obvious catalytic effects for cellulose and sawdust, but for straw there were insignificant differences in accumulative gas yields between two cases (Ni-CaO-Ca $\mathrm{SiO}_{4}$ and $\mathrm{Ni}-\mathrm{Ca}_{2} \mathrm{SiO}_{4}$ ). The two functional materials just showed little catalytic effect on $\mathrm{CO}_{2}$ accumulative yield. The discrepancies of the gas yield and influence of functional materials among these three samples could be attributed to the differences in elemental composition, and physical and chemical structure.

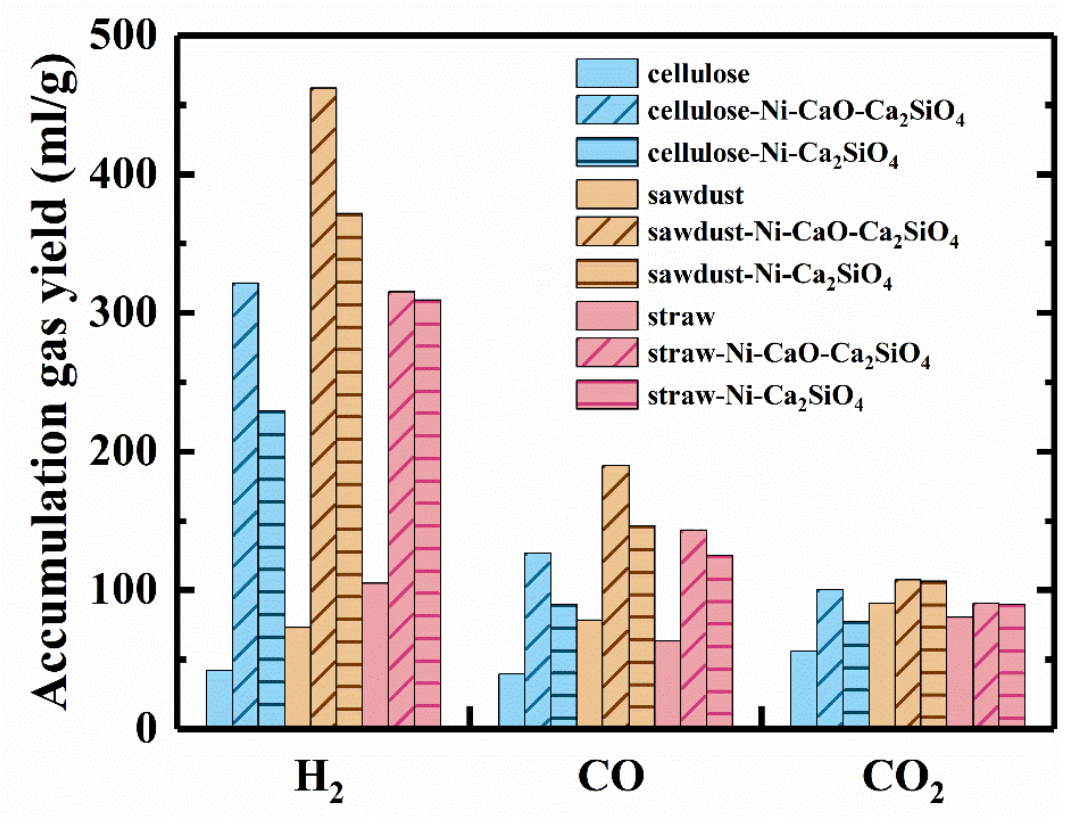

Fig. 4 Accumulative gas $\left(\mathrm{H}_{2}, \mathrm{CO}, \mathrm{CO}_{2}\right)$ yield of cellulose, sawdust and straw under three catalytic conditions (no catalyst, $\mathrm{Ni}-\mathrm{CaO}-\mathrm{Ca}_{2} \mathrm{SiO}_{4}$ and $\mathrm{Ni}-\mathrm{Ca}_{2} \mathrm{SiO}_{4}$ ).

3.3. Kinetic analysis of biomass catalytic pyrolysis 

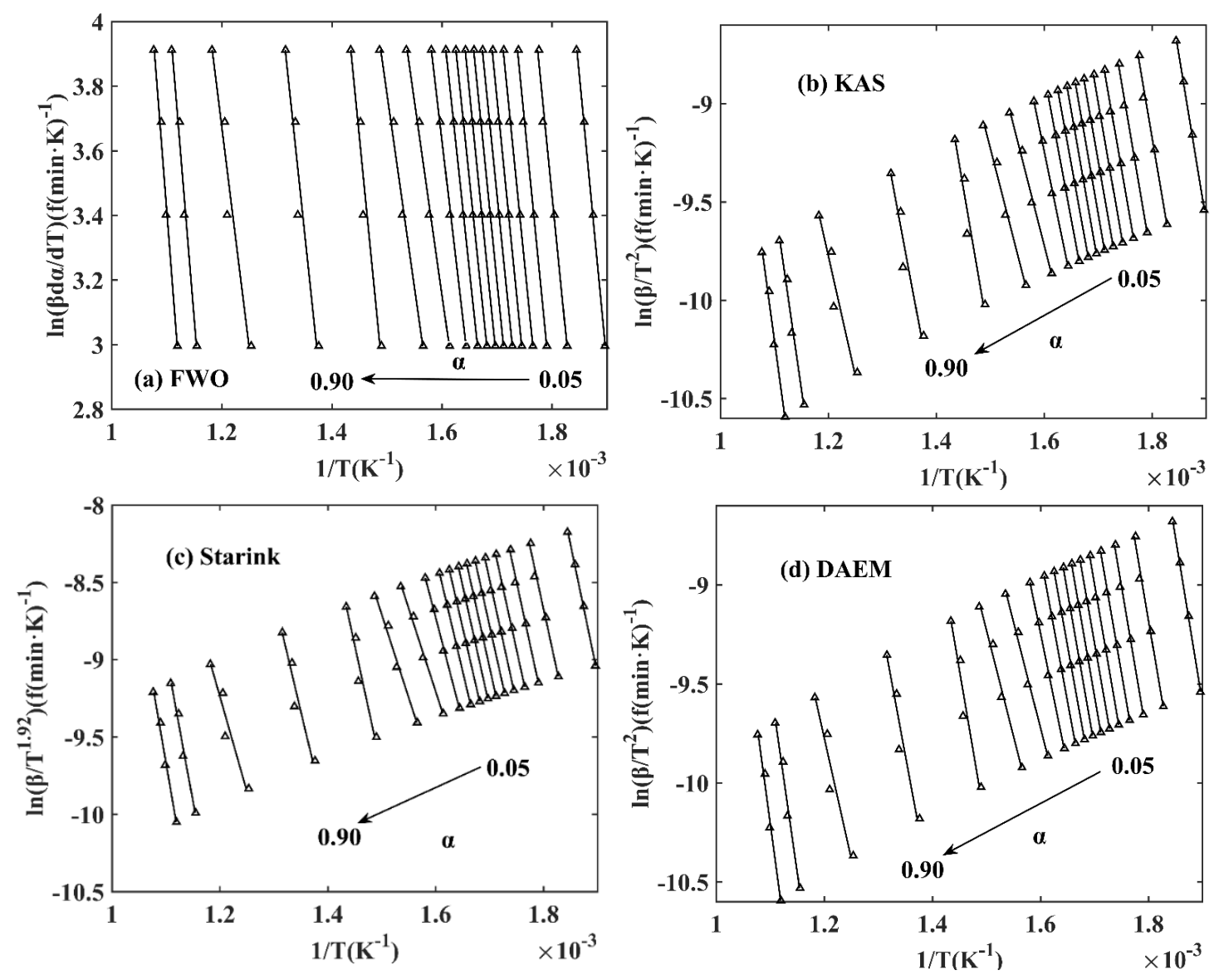

Fig. 5. Arrhenius plot of straw with $\mathrm{Ni}-\mathrm{CaO}-\mathrm{Ca}_{2} \mathrm{SiO}_{4}$ at different degrees from: (a) FWO method, (b) KAS method, (c) Starink method, and (d) DAEM

Kinetics of biomass catalytic pyrolysis were determined using four model-free isoconversion methods at selected degrees of conversion $\alpha$ ranging from 0.05 to 0.90 . Fig. 5. shows the Arrhenius plot of straw with $\mathrm{Ni}-\mathrm{CaO}-\mathrm{Ca}_{2} \mathrm{SiO}_{4}$ at different degrees derived from: (a) FWO method, (b) KAS method, (c) Starink method and (d) DAEM, where the arrow means the increasing direction of conversion $\alpha$ at intervals of 0.05 . The results for all biomasses under other catalytic conditions were also transformed to Arrhenius plots with the four methods as shown in SI Fig. S1 S8. The activation energy $E$ and the correlation $\mathrm{R}^{2}$ of all samples with the four methods are listed in SI Table. S1 S3 and overall correlation $\mathrm{R}^{2}$ was above 0.9 , which indicated that FWO method, KAS method, Starink method and DAEM were suitable for modeling the biomass catalytic pyrolysis. These tables show that the pyrolysis of cellulose under the three cases was easier to model by the four methods than sawdust and straw due to 
the higher correlation $\mathrm{R}^{2}$, which may be a result caused by multiple effects of catalytic inorganic substances and the complex organic composition. At the conversion stages $\alpha=0.70-0.80$ for straw with $\mathrm{Ni}-\mathrm{CaO}-\mathrm{Ca}_{2} \mathrm{SiO}_{4}$, and $\alpha=0.80-0.85$ for sawdust with $\mathrm{Ni}-\mathrm{CaO}-\mathrm{Ca}_{2} \mathrm{SiO}_{4}$, the correlation $\mathrm{R}^{2}$ was between 0.918 and 0.942 , which highlighted a lower degree of agreement between the model fitting and the experimental data. This might be caused by the interferential effects of interaction between $\mathrm{CaO}$ and complex biomass, straw and sawdust.

The activation energies (shown in Table. S1 S3) calculated using the KAS method and DAEM were the same due to the same Arrhenius plots were both obtained by plotting $\ln \left(\beta / T^{2}\right)$ vs $1 / T$. It also shows that the results of $E$ obtained by using Starink method were slightly different with those from KAS method (and DAEM). Consequently, for cellulose, sawdust and straw, under three catalytic conditions (no catalyst, $\mathrm{Ni}-\mathrm{CaO}-\mathrm{Ca}_{2} \mathrm{SiO}_{4}$ and $\mathrm{Ni}-\mathrm{Ca}_{2} \mathrm{SiO}_{4}$ ), the plots of activation energy $E$, from FWO method and DAEM, against conversion $\alpha$ are shown in Fig. 6. The two activation energy curves showed that a similar tendency with conversion and addition of functional material. The values of $E$ from the FWO method generally were higher than those from DAEM, which is consistent with the findings by Yuan et al. at conversions below 0.75 [39]. 

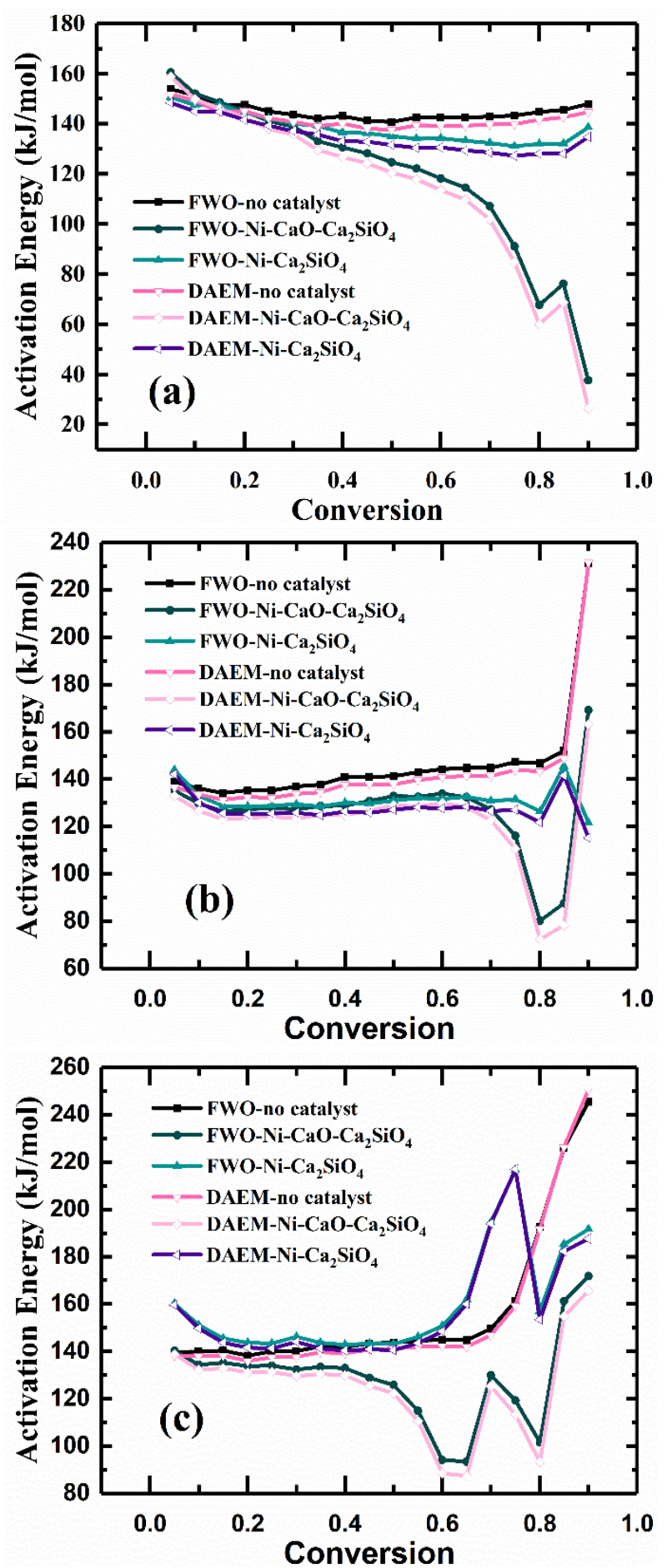

Fig. 6. Change of activation energy as a function of conversion for (a) cellulose, (b) sawdust and (c) straw under three catalytic conditions (no catalyst, $\mathrm{Ni}-\mathrm{CaO}-\mathrm{Ca}_{2} \mathrm{SiO}_{4}$ and $\mathrm{Ni}-\mathrm{Ca}_{2} \mathrm{SiO}_{4}$ ) derived from FWO method and DAEM.

As shown in Fig. 6(a), for the pyrolysis of cellulose without catalyst the value of activation energy is within a range from 137.6-153.7 kJ/mol, while Dahiya et al. obtained the range from 158.9-168.1 kJ/mol and Draman et al. obtained the range from 160.6-203.5 kJ/mol by using FWO method [47, 48]. These differences could be 
attributed to the difference of feedstocks in each of the studies. In Fig. 6(a). the activation energy under different catalytic conditions clearly illustrated that the functional materials, both $\mathrm{Ni}-\mathrm{CaO}-\mathrm{Ca}_{2} \mathrm{SiO}_{4}$ and $\mathrm{Ni}-\mathrm{Ca}_{2} \mathrm{SiO}_{4}$, decreased the activation energy of pyrolysis. For the cellulose pyrolysis with $\mathrm{Ni}_{-} \mathrm{Ca}_{2} \mathrm{SiO}_{4}$, the range of $E$ was from $127.1-150.5 \mathrm{~kJ} / \mathrm{mol}$ and at stage $\alpha=0.35-0.90$ The decrease in $E$ was more obvious which indicated the catalytic effect of $\mathrm{Ni}$ on $\mathrm{O}-\mathrm{H}$ and $\mathrm{C}-\mathrm{H}$ cleavage to produce more $\mathrm{H}_{2}$ as evidenced in Fig. 2(a). At a conversion in the range $\alpha=0.70-0.90$, corresponding to the little peak around $400-450{ }^{\circ} \mathrm{C}$ in Fig. 2(a), the decrease of activation energy was caused by the addition of $\mathrm{CaO}$, which illustrated that $\mathrm{CaO}$ has the catalytic effect for biomass pyrolysis. At the conversion $\alpha=0.90$ the corresponding temperature was $591.1^{\circ} \mathrm{C}$, which was the beginning temperature of the secondary peak in Fig. 3, thus again might be correlated to the activity of $\mathrm{CaO}$.

In Fig. 6(b) the $E$ of sawdust without catalyst was found to increase with conversion over the conversion range of 0.10 to 0.85 , while the lowest $E$ was 133.6 $\mathrm{kJ} / \mathrm{mol}$ (DAEM) and the highest is $148.8 \mathrm{~kJ} / \mathrm{mol}$. At conversion of 0.90 the $E$ increased to $231.7 \mathrm{~kJ} / \mathrm{mol}$ (DAEM). During the conversion range $\alpha=0.05-0.65$, the Ni-CaO-Ca $-\mathrm{SiO}_{4}$ and $\mathrm{Ni}-\mathrm{Ca}_{2} \mathrm{SiO}_{4}$ had similar effects on activation energy. For the case of sawdust with $\mathrm{Ni}-\mathrm{CaO}-\mathrm{Ca}_{2} \mathrm{SiO}_{4}$, a lower activation energy was observed compared to the case of sawdust with $\mathrm{Ni}-\mathrm{Ca}_{2} \mathrm{SiO}_{4}$, over the conversion range $\alpha=$ $0.65-0.85$, which could be explained by the presence of $\mathrm{CaO}$ that can promote the cracking of small organic molecules from the pyrolysis of large organic molecules.

In Fig. 6(c), the $E$ of the straw without catalyst case was within the range of 136.0-250.6 kJ/mol, while there was a rapid increase of $E$ observed over the conversion range of 0.65 to 0.90 . The case of straw with $\mathrm{Ni}_{-} \mathrm{Ca}_{2} \mathrm{SiO}_{4}$ showed an obvious increase of activation energy at stage $\alpha=0.60-0.75$ contradicting the catalytic effects of $\mathrm{Ni}$, while the corresponding temperature range of this stage was $350-400{ }^{\circ} \mathrm{C}$. Combined with Fig. 2(c) and F.3 (c) the gas yield rate over this temperature range showed smaller peaks than other of cases (cellulose and sawdust with $\mathrm{Ni}-\mathrm{Ca}_{2} \mathrm{SiO}_{4}$ ). 
As shown in Table. 1 the ash content was $11.63 \%$ which indicated the functional material $\left(\mathrm{Ni}-\mathrm{Ca}_{2} \mathrm{SiO}_{4}\right)$ may prevent the pyrolysis at this stage due to the interaction between the functional material and inorganic substance of straw. The increase of $\mathrm{H}_{2}$ and $\mathrm{CO}$ in Fig. 2(c) and Fig. 3(c) and the decline of $E$ at the stage $\alpha=0.80-0.90$ both implied that $\mathrm{Ni}$ had a catalytic effect in breaking of light organic molecules to produce $\mathrm{H}_{2}$ and $\mathrm{CO}$. CaO presented an obvious catalytic effect during the conversion stage $\alpha=$ 0.60-0.80, corresponding the breakage of both large and small organic molecules.

More activation energies were obtained by changing the interval of conversion into 0.01 , based on DAEM, and the distribution of activation energies of pyrolysis of three biomass types was shown in Fig. S9 S11. In Fig. S9 the $\mathrm{Ni}-\mathrm{Ca}_{2} \mathrm{SiO}_{4}$ and $\mathrm{Ni}-\mathrm{CaO}-\mathrm{Ca}_{2} \mathrm{SiO}_{4}$ showed an obvious decrease in pyrolysis activation energy of cellulose with $\mathrm{Ni}-\mathrm{CaO}-\mathrm{Ca}_{2} \mathrm{SiO}_{4}$ functional material and resulted in the dispersion of $E$ from $20-160 \mathrm{~kJ} / \mathrm{mol}$. In Fig. S10, the case of sawdust with $\mathrm{Ni}_{-} \mathrm{Ca}_{2} \mathrm{SiO}_{4}$ showed that the activation energy decreased and centralized around $127.5 \mathrm{~kJ} / \mathrm{mol}$, and the case of sawdust with Ni-CaO-Ca $\mathrm{SiO}_{4}$ showed the reduction of $E$ compared with the case of sawdust with $\mathrm{Ni}-\mathrm{Ca}_{2} \mathrm{SiO}_{4}$. As shown in Fig. S11, the case of straw without catalyst had widespread activation energy distribution and the case of straw with $\mathrm{Ni}-\mathrm{Ca}_{2} \mathrm{SiO}_{4}$ showed an increase of activation energy, which was related to the inorganic content of the straw. Cellulose, sawdust and straw without catalyst showed a similar pyrolysis activation energy, but the addition of the functional materials generally led to lower a pyrolysis activation energy.

In SI Table. S4, the frequency factors $k_{0}$ and $E$-distribution had been calculated by using DAEM. The $E$ and $k_{0}$ from DAEM were used to obtain calculated conversion results of cellulose, sawdust and straw under three catalytic conditions (no catalyst, $\mathrm{Ni}-\mathrm{CaO}-\mathrm{Ca}_{2} \mathrm{SiO}_{4}$ and $\mathrm{Ni}-\mathrm{Ca}_{2} \mathrm{SiO}_{4}$ ) at $50{ }^{\circ} \mathrm{C} / \mathrm{min}$ heating rate. It is shown in Fig. 7 that the calculated results for catalytic pyrolysis were in good agreement with the experimental data. The suitability of the DAEM to study biomass catalytic pyrolysis was then confirmed. 

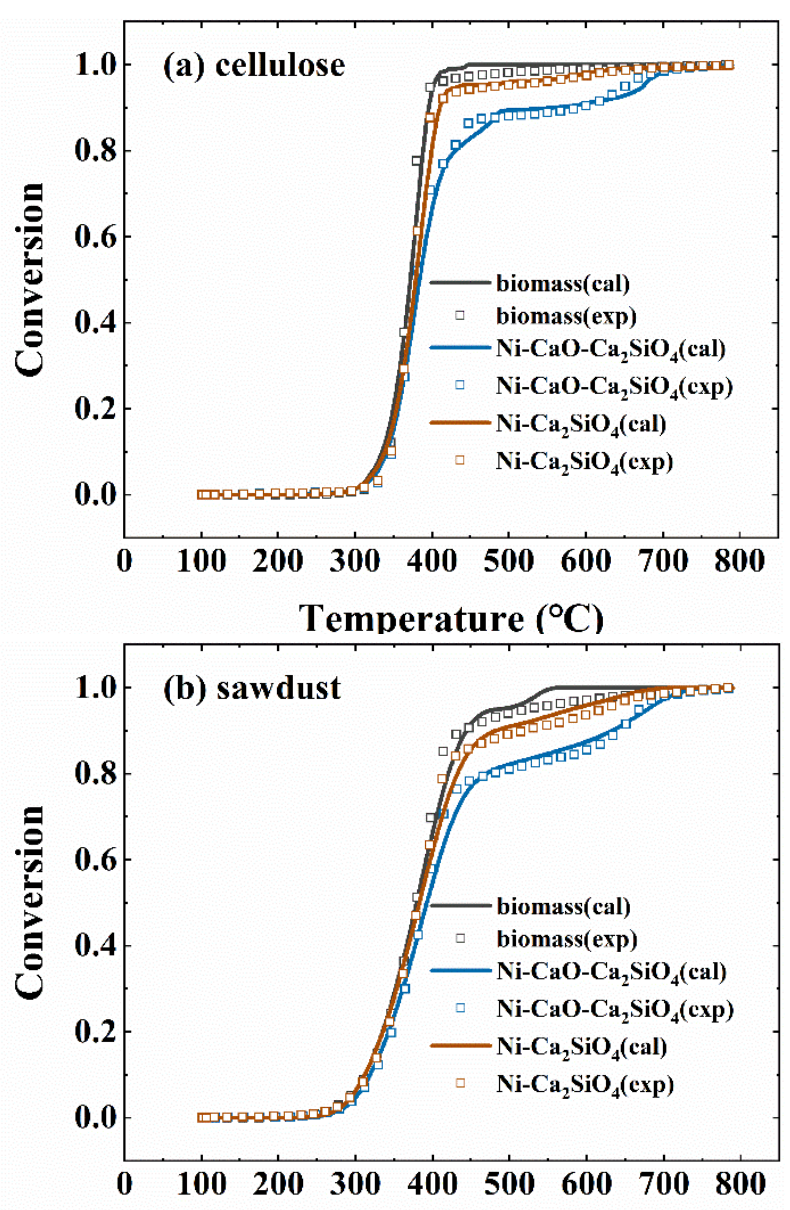

Temperature $\left({ }^{\circ} \mathrm{C}\right)$

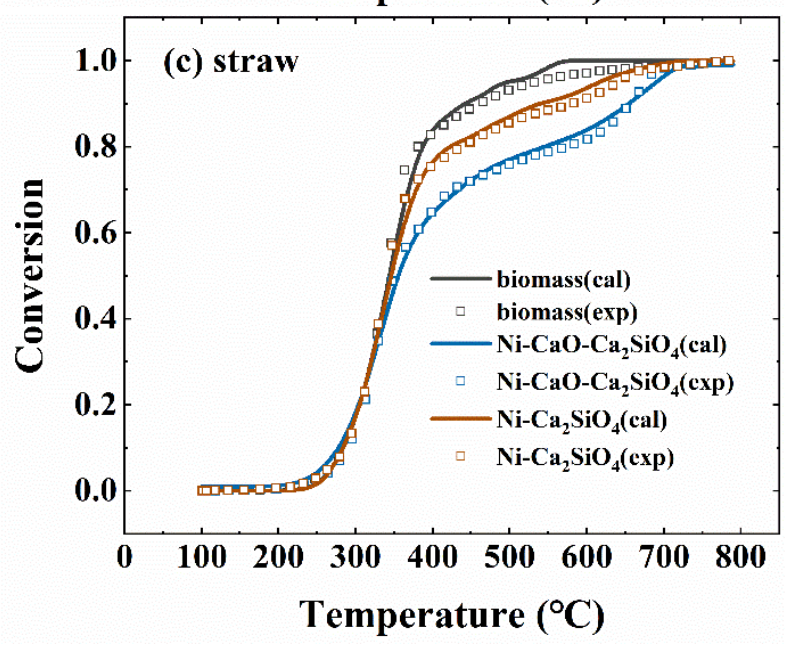

Fig. 7. Fitting results for pyrolysis of (a) cellulose, (b) sawdust and (c) straw with three cases (no catalyst, $\mathrm{Ni}-\mathrm{CaO}-\mathrm{Ca}_{2} \mathrm{SiO}_{4}$ and $\mathrm{Ni}-\mathrm{Ca}_{2} \mathrm{SiO}_{4}$ ) from DAEM method.

\section{Conclusion}

In this study, the pyrolysis behaviors of three kinds of biomasses (cellulose, sawdust and straw) in three catalytic conditions (no catalyst, $\mathrm{Ni}-\mathrm{CaO}-\mathrm{Ca}_{2} \mathrm{SiO}_{4}$ and $\mathrm{Ni}-\mathrm{Ca}_{2} \mathrm{SiO}_{4}$ ) were investigated by TGA. The yield rates of gases, $\mathrm{H}_{2}, \mathrm{CO}$ and $\mathrm{CO}_{2}$, 
were measured by mass spectrometry synchronously. For kinetic analysis, the activation energies $E$, were obtained by using four isoconversional analysis methods (FWO method, KAS method, Starink method and DAEM). The conclusions are as follows:

1. The functional materials, $\mathrm{Ni}-\mathrm{CaO}-\mathrm{Ca}_{2} \mathrm{SiO}_{4}$ and $\mathrm{Ni}-\mathrm{Ca}_{2} \mathrm{SiO}_{4}$, showed an obvious catalytic effect to produce $\mathrm{H}_{2}$ and $\mathrm{CO}$, for the three types of biomass samples tested. For sawdust and straw, functional materials exhibited little catalytic effect in producing greater $\mathrm{CO}_{2}$ accumulative yield. $\mathrm{CaO}$ showed a more obvious catalytic effect for cellulose and sawdust than straw.

2. The correlation $\mathrm{R}^{2}$ of all fitting lines in all cases was above 0.9 , which indicated that FWO method, KAS method, Starink method and DAEM were suitable for modeling the kinetics of biomass catalytic pyrolysis. The activation energy curves showed a consistent trend with conversion and the addition of functional materials.

3. For the three types of biomasses tested, the functional material, Ni-CaO-Ca $\mathrm{SiO}_{4}$, showed the greatest catalytic effect on pyrolysis due to the evident decrease in activation energy. For cellulose and sawdust, the functional material, $\mathrm{Ni}_{-} \mathrm{Ca}_{2} \mathrm{SiO}_{4}$, also showed a catalytic effect according to the variation of the measured activation energy. On the contrary, for straw pyrolysis $\mathrm{Ni}-\mathrm{Ca}_{2} \mathrm{SiO}_{4}$ resulted the increase of activation energy, which might be related to the higher inorganic content of straw.

\section{Acknowledgements}

This work was supported by the National Natural Science Foundation of China (grant number: 51506112). G. J. would appreciate the financial support from the Fundamental Research Funds for the Central Universities (grant number: DUT18RC(3)036)

\section{Reference}

[1] P. McKendry, Energy production from biomass (Part 1): overview of biomass, Bioresour. Technol. 83 (2002) 37-46. 
[2] H. Kopetz, Renewable resources: build a biomass energy market, Nature 494 (2013) 29-31.

[3] M.F. Demirbas, M. Balat, Recent advances on the production and utilization trends of bio-fuels: a global perspective, Energy Convers. Manage. 47 (2006) 2371-2381.

[4] B. Steubing, R. Zah, P. Waeger, C. Ludwig, Bioenergy in Switzerland: Assessing the domestic sustainable biomass potential, Renew. Sust. Energ. Rev. 14 (2010) 2256-2265.

[5] H.L. Long, X.B. Li, H. Wang, J.D. Jia, Biomass resources and their bioenergy potential estimation: A review, Renew. Sust. Energ. Rev. 26 (2013) 344-352.

[6] L. Ding, K. Yoshikawa, M. Fukuhara, D. Xin, L. Muhan, Development of an ultra-small biomass gasification and power generation system: Part 1. A novel carbonization process and optimization of pelletization of carbonized wood char, Fuel 210 (2017) 674-683.

[7] J. Chen, Y. He, J. Liu, C. Liu, W. Xie, J. Kuo, X. Zhang, S. Li, J. Liang, S. Sun, M. Buyukada, F. Evrendilek, The mixture of sewage sludge and biomass waste as solid biofuels: process characteristic and environmental implication, Renew. Energ. 139 (2019) 707-717.

[8] J. Gao, A. Zhang, S.K. Lam, X. Zhang, A.M. Thomson, E. Lin, K. Jiang, L.E. Clarke, J.A. Edmonds, P.G. Kyle, An integrated assessment of the potential of agricultural and forestry residues for energy production in China, Global Change Biology Bioenergy 8 (2016) 880-893.

[9] P. McKendry, Energy production from biomass (Part 2): conversion technologies, Bioresour. Technol. 83 (2002) 47-54.

[10] T. Sonobe, N. Worasuwannarak, Kinetic analyses of biomass pyrolysis using the distributed activation energy model, Fuel 87 (2008) 414-421.

[11] A.L.F.S. d'Almeida, D.W. Barreto, V. Calado, J.R.M. d'Almeida, Thermal analysis of less common lignocellulose fibers, J. Therm. Anal. Calorim. 91 (2007) 405-408. 
[12] A.J. Tsamba, W. Yang, W. Blasiak, Pyrolysis characteristics and global kinetics of coconut and cashew nut shells, Fuel Process. Technol. 87 (2006) 523-530.

[13] Q.G. Xiong, J.C. Zhang, F. Xu, G. Wiggins, C.S. Daw, Coupling DAEM and CFD for simulating biomass fast pyrolysis in fluidized beds, J. Anal. Appl. Pyrolysis 117 (2016) 176-181.

[14] S.R. Wang, B. Ru, H.Z. Lin, G.X. Dai, Y.R. Wang, Z.Y. Luo, Kinetic study on pyrolysis of biomass components: a critical review, Curr. Org. Chem. 20 (2016) 2489-2513.

[15] S. Vyazovkin, A.K. Burnham, J.M. Criado, L.A. Pérez-Maqueda, C. Popescu, N. Sbirrazzuoli, ICTAC Kinetics Committee recommendations for performing kinetic computations on thermal analysis data, Thermochim. Acta 520 (2011) 1-19.

[16] S. Vyazovkin, K. Chrissafis, M.L. Di Lorenzo, N. Koga, M. Pijolat, B. Roduit, N. Sbirrazzuoli, J.J. Suñol, ICTAC Kinetics Committee recommendations for collecting experimental thermal analysis data for kinetic computations, Thermochim. Acta 590 (2014) 1-23.

[17] S. Vyazovkin, Isoconversional kinetics of polymers: the decade past, Macromol. Rapid Commun. 38 (2017) 21.

[18] J.E. White, W.J. Catallo, B.L. Legendre, Biomass pyrolysis kinetics: a comparative critical review with relevant agricultural residue case studies, J. Anal. Appl. Pyrolysis 91 (2011) 1-33.

[19] S. Wang, H. Lin, B. Ru, G. Dai, X. Wang, G. Xiao, Z. Luo, Kinetic modeling of biomass components pyrolysis using a sequential and coupling method, Fuel 185 (2016) 763-771.

[20] G. Pitt, The kinetic of the evolution of volatile products from coal, Fuel 41 (1962) 267-274.

[21] K. Miura, A new and simple method to estimate $\mathrm{f}(\mathrm{E})$ and $\mathrm{k} 0(\mathrm{E})$ in the distributed activation energy model from three sets of experimental data, Energy Fuels 9 (1995) 302-307. 
[22] J.M. Cai, W.X. Wu, R.H. Liu, An overview of distributed activation energy model and its application in the pyrolysis of lignocellulosic biomass, Renew. Sust. Energ. Rev. 36 (2014) 236-246.

[23] K. Kirtania, S. Bhattacharya, Coupling of a distributed activation energy model with particle simulation for entrained flow pyrolysis of biomass, Fuel Process. Technol. 137 (2015) 131-138.

[24] H. Cai, J. Liu, W. Xie, J. Kuo, M. Buyukada, F. Evrendilek, Pyrolytic kinetics, reaction mechanisms and products of waste tea via TG-FTIR and Py-GC/MS, Energy Convers. Manage. 184 (2019) 436-447.

[25] G.Z. Ji, X.Y. Xu, H. Yang, X. Zhao, X. He, M. Zhao, Enhanced hydrogen production from sawdust decomposition using hybrid-functional Ni-CaO-Ca2SiO4 materials, Environ. Sci. Technol. 51 (2017) 11484-11492.

[26] M. Zhao, X. Yang, T.L. Church, A.T. Harris, technology, Novel CaO-SiO2 sorbent and bifunctional $\mathrm{Ni} / \mathrm{Co}-\mathrm{CaO} / \mathrm{SiO} 2$ complex for selective $\mathrm{H} 2$ synthesis from cellulose, Environ. Sci. Technol. 46 (2012) 2976-2983.

[27] K. Akubo, M.A. Nahil, P.T. Williams, Pyrolysis-catalytic steam reforming of agricultural biomass wastes and biomass components for production of hydrogen/syngas, J. Energy Inst. (2018).

[28] D.M. Alonso, J.Q. Bond, J.A. Dumesic, Catalytic conversion of biomass to biofuels, Green Chem. 12 (2010) 1493-1513.

[29] S. De, B. Saha, R. Luque, Hydrodeoxygenation processes: advances on catalytic transformations of biomass-derived platform chemicals into hydrocarbon fuels, Bioresour. Technol. 178 (2015) 108-118.

[30] M.M. Rahman, R. Liu, J. Cai, Catalytic fast pyrolysis of biomass over zeolites for high quality bio-oil - A review, Fuel Process. Technol. 180 (2018) 32-46.

[31] B. Lin, Q. Huang, Y. Chi, Co-pyrolysis of oily sludge and rice husk for improving pyrolysis oil quality, Fuel Process. Technol. 177 (2018) 275-282.

[32] J. Yan, Z. Zhang, Carbon capture, utilization and storage (CCUS), Appl. Energy 
235 (2019) 1289-1299.

[33] A. Cruz-Hernández, J.A. Mendoza-Nieto, H. Pfeiffer, NiO CaO materials as promising catalysts for hydrogen production through carbon dioxide capture and subsequent dry methane reforming, J. Energy Chem. 26 (2017) 942-947.

[34] M. Zhao, T.L. Church, A.T. Harris, SBA-15 supported Ni-Co bimetallic catalysts for enhanced hydrogen production during cellulose decomposition, Appl. Catal. B 101 (2011) 522-530.

[35] M. Zhao, X. Yang, T.L. Church, A.T. Harris, Interaction between a bimetallic NiCo catalyst and micrometer-sized $\mathrm{CaO}$ for enhanced $\mathrm{H} 2$ production during cellulose decomposition, Int. J. Hydrog. Energy 36 (2011) 421-431.

[36] M. Zhao, N.H. Florin, A.T. Harris, Mesoporous supported cobalt catalysts for enhanced hydrogen production during cellulose decomposition, Appl. Catal. B 97 (2010) 142-150.

[37] M. Zhao, N.H. Florin, A.T. Harris, The influence of supported Ni catalysts on the product gas distribution and H2 yield during cellulose pyrolysis, Appl. Catal. B 92 (2009) 185-193.

[38] M. Wang, Z. Chen, J. Lv, Y. Ren, Y. Jiang, E. Jiang, D. Wang, Combustion characteristics and kinetic analysis of heavy tar from continuous pyrolysis of camellia shell, Fuel Process. Technol. 176 (2018) 131-137.

[39] X. Yuan, T. He, H. Cao, Q. Yuan, Cattle manure pyrolysis process: kinetic and thermodynamic analysis with isoconversional methods, Renew. Energ. 107 (2017) 489-496.

[40] K. Miura, T. Maki, A simple method for estimating $f(E)$ and $\mathrm{k} 0(\mathrm{E})$ in the distributed activation energy model, Energy Fuels 12 (1998) 864-869.

[41] C. Lu, W. Song, W. Lin, Kinetics of biomass catalytic pyrolysis, Biotechnol. Adv. 27 (2009) 583-587.

[42] J.H. Flynn, L.A. Wall, General treatment of the thermogravimetry of polymers, Journal of Research of the National Bureau of Standards Section A: Physics and 
Chemistry 70A (1966) 487-523.

[43] H.E. Kissinger, Reaction kinetics in differential thermal analysis, Anal. Chem. 29 (1957) 1702-1706.

[44] M.J. Starink, A new method for the derivation of activation energies from experiments performed at constant heating rate, Thermochim. Acta 288 (1996) 97-104.

[45] V. Vand, A theory of the irreversible electrical resistance changes of metallic films evaporated in vacuum, P. Phys. Soc. 55 (1943) 0222-0246.

[46] H. Wang, Z. Chen, X. Zhang, Z. Li, N. Fang, X. Liu, Thermal decomposition mechanisms of coal and coal chars under $\mathrm{CO} 2$ atmosphere using a distributed activation energy model, Thermochim. Acta 662 (2018) 41-46.

[47] J.B. Dahiya, K. Kumar, M. Muller-Hagedorn, H. Bockhorn, Kinetics of isothermal and non-isothermal degradation of cellulose: model-based and model-free methods, Polym. Int. 57 (2008) 722-729.

[48] S.F.S. Draman, R. Daik, F.A. Latif, S.M. El-Sheikh, Characterization and thermal decomposition kinetics of kapok (Ceiba pentandra L.)-based cellulose, Bioresources 9 (2014) 8-23. 